\title{
OSCILLATION CRITERIA FOR NEUTRAL PARTIAL FUNCTIONAL DIFFERENTIAL EQUATIONS
}

\section{Run XU AND FANWEI MENG}

Abstract. Some new oscillation criteria are established for second order neutral partial functional differential equations of the form

$$
\begin{aligned}
\frac{\partial}{\partial t}\left[p(t) \frac{\partial}{\partial t}\left(u(x, t)+\sum_{i=1}^{l} \lambda_{i}(t) u\left(x, t-\tau_{i}\right)\right)\right] & \\
=a(t) \Delta u(x, t)+\sum_{k=1}^{s} a_{k}(t) \Delta u\left(x, t-\rho_{k}(t)\right)-q(x, t) u(x, t) & \\
& -\sum_{j=1}^{m} q_{j}(x, t) f_{j}\left(u\left(x, t-\sigma_{j}\right)\right),(x, t) \in \Omega \times[0, \infty) \equiv G,
\end{aligned}
$$

by integral average, where $\Omega$ is a bounded domain in $\mathbb{R}^{N}$ with a piecewise smooth boundary $\partial \Omega$ and $\Delta$ is the Laplacian in the Euclidean $N$-space $\mathbb{R}^{N}$.

Mathematics subject classification (2010): 34C10.

Keywords and phrases: partial differential equations, damping term, oscillatory solutions, second order, asymptotic behavior.

\section{REFERENCES}

[1] D. Bainov, B.T. CUI AND E. Minchev, Forced oscillation of solutions of certain hyperbolic equations of neutral type, J. Comput. Appl. Math., 72, (1996), 309-318.

[2] B.T. CUI, Oscillation properties for parabolic equations of neutral type, Comment. Math. Univ. Carolin., 33, (1992), 581-588.

[3] B.T. CUI, Oscillation properties of the solutions of hyperbolic equations with deviating arguments, Demonstration Math., 29, (1996), 61-68.

[4] B.T. CUI, Y.H. YU AND S.Z. Lin, Oscillation of solutions of delay hyperbolic differential equations, Acta Math. Appl. Sinica., 19, (1996), 80-88 [in Chinese].

[5] X.L. Fu, W. Zhuang, Oscillation of neutral delay parabolic equations, J. Math. Anal. Appl., 191, (1995), 473-489.

[6] B.S. LALLI, Y.H. YU AND B.T. CUi, Oscillation of hyperbolic equations with functional arguments, Appl. Math.Comput. 53, (1993), 97-110.

[7] Wei NiAn Li AND BaO TONG CUi, Oscillation of solutions of neutral partial functional differential equations, J. Math. Anal. Appl., 234, (1999), 123-146.

[8] D.P. MisheV, D.D. BAINOV, Oscillation of the solutions of parabolic differential equations of neutral type, Appl. Math. Comput., 28, (1998), 97-111.

[9] JiZHONG WANG, FANWEI MENG, SANYANG LiU, Integral average method for oscillation of second order partial differential equations with delays, Appl. Math. Comput., 187, (2007), 815-823.

[10] Run Xu, FANweI Meng, Some new oscillation criteria for second order quasi-linear neutral delay differential equations, Appl. Math. Comput., 182, (2006), 797-803. 